\title{
Three-Question Depression Screener Used for Lumbar Disc Herniations and Spinal Stenosis
}

\author{
Howard I. Levy, MD, ${ }^{*}$ Brett Hanscom, MS, † and Scott D. Boden, MD,
}

Study Design. A depression screener was used to determine positive responses amongst patients with two disorders commonly treated with surgery.

Objective. To examine the relation between positive responses to the depression screener and pain characteristics, sociodemographic responses, and Short-Form 36Item Health Survey subscale scores among patients with lumbar disc herniation or spinal stenosis.

Summary of Background Data. Numerous studies have reported a correlation between depression and low back pain, but few have examined this relation among patients with a diagnosis of sciatica from lumbar disc herniation or spinal stenosis. The Health Status Questionnaire 2.0 includes both the Short-Form 36-Item Health Survey (a validated, multidimensional, generic instrument measuring health-related quality of life and functional status) and the three-question depression screener.

Methods. The database of the National Spine Network (a nonprofit collaboration of physicians caring for patients with back and neck problems that pools patient data) was queried for patients 18 to 65 years of age with a diagnosis of lumbar disc herniation $(n=2878)$ and patients 30 to 80 years of age with a diagnosis of spinal stenosis $(n=3801)$. Depression screeners scored positive when patients reported depressive symptoms within the year to any question about symptoms.

Results. The screener elicited positive responses from $36.4 \%$ of the patients with spinal stenosis and $38.4 \%$ of the patients with lumbar disc herniation. Among the patients with spinal stenosis or lumbar disc herniation, those with positive depression screener responses reported longer duration of symptoms ( $>7$ weeks) and failure to improve. They were more likely to be obese, recipients of workers' compensation, unmarried, and less educated (below Grade 12). In multivariate analyses, positive depression screener responses were significantly associated with an attorney's services and a longer duration of symptoms.

Conclusions. A positive depression screener response is strongly associated with poorer functional status and health-related quality of life, as measured by the ShortForm 36-Item Health Survey, among patients with lumbar disc herniation or spinal stenosis, and higher symptom intensity. [Key words: lumbar disc herniation, pain, SF-36, depression, spinal stenosis, three-question depression screener] Spine 2002;27:1232-1237
From the *Emory Spine Center, Emory University School of Medicine, Decatur, Georgia, and the †Dartmouth Medical School, Hanover, New Hampshire.

Acknowledgment date: March 13, 2001.

First revision date: August 30, 2001.

Acceptance date: November 21, 2001.

The manuscript submitted does not contain information about medical devices or drugs.

No funds were received in support of this work. No benefits in any form have been or will be received from a commercial party related directly or indirectly to the subject of this manuscript.
Lumbar spinal stenosis and lumbar disc herniations are the most frequent reasons for lumbar surgery. ${ }^{15}$ Outcomes of surgery for these disorders are very favorable when performed with proper indications. However, there is a subset of patients who do not improve despite very good indications for surgery. Depression and other psychological issues may be important in identifying those patients at increased risk of poor outcomes. ${ }^{8}$

The association between low back pain and depression has been reported previously. ${ }^{5-7,12}$ Depression may precede or follow the development of low back pain. The traditional instrument for detecting depression, the Minnesota Multiphasic Personality Inventory, is impractical for use as a screener because it is time consuming, cumbersome, and covers voluminous material. Consequently, several shorter depression instruments such as the Beck Depression Inventory and the Center for Epidemiologic Studies-Depression Scale (CES-D) have been developed. ${ }^{3,13}$ However, neither of these instruments is as short and easy to administer as the new three-question depression screener. Additionally, scoring of the screener requires only a glance and no calculation. This screener has a demonstrated specificity exceeding $90 \%$ and a sensitivity of $83 \%$ to $94 \%$ for detecting depression. ${ }^{14}$

The screener was developed by taking a pool of eight questions: two from the Diagnostic Interview Schedule and six from the CES-CD. ${ }^{14}$ Logistics regression was used to remove the questions that contributed least to accurate prediction of depression or dysthymia. ${ }^{14}$ Three questions remained to form the depression screener: two from the Diagnostic Interview Schedule and one from the CES-CD. This screener has been added to the ShortForm 36-Item Health Survey (SF-36), a medical outcomes study instrument that assesses general health and well-being. Recently the SF-36 has been used to assess outcomes from spine surgery for scoliosis and lumbar radiculopathy. ${ }^{1,2}$ Albert et $\mathrm{al}^{1}$ found improvement in all SF-36 scales at a 2-year follow-up assessment for lumbar laminectomy and adult deformity surgery. ${ }^{2}$

At this writing, no study has investigated whether depression is associated with symptom severity in patients with spinal stenosis or lumbar disc herniations. Most clinicians agree that depressed patients address somatic pain problems readily. The goal of this study was to determine the prevalence of positive scores on the threequestion depression screener among patients with the diagnosis of lumbar spinal stenosis or lumbar disc herniations. Furthermore, the association between a posi- 
tive depression screener result and pain, symptom severity, and SF-36 scores was assessed.

\section{Methods}

The National Spine Network Database. The National Spine Network (NSN) is a nonprofit organization of physicians who care for patients with back and neck problems, collaborating to collect data on their patients for research purposes. The NSN patient data collection form consists of questions relating to demographics, work status, medication use, general health status, and specific spine-related pain symptoms. General health status is measured using the Health Status Questionnaire 2.0 (HSQ 2.0; Health Outcomes Institute, Bloomington, $\mathrm{MN}$ ), which contains the SF-36 and the three-question depression screener. Spine-related symptoms are rated along a 6-point scale with choices ranging from 0 (none) to 5 (severe). The NSN physician data collection form consists of questions relating to pain symptoms, surgical history, comorbidity, diagnosis, and treatment plan. Both patient and physician data are stored in the NSN database.

The Three-Question Depression Screener and the ShortForm 36-Item Health Survey. The three-question depression screener shown in Figure 1 was used to measure depression responses when patients reported any depression symptoms within the preceding year. A positive response to either Question 37 or Question 39 on the HSQ 2.0 was considered a "positive depression screener." The response to Question 38 had no impact on the result of the depression screener. All the patients were categorized as having either a "positive" or "negative" depression screener response.

The eight SF-36 scales (bodily pain, physical function, role physical, general health, vitality, role emotional, social function, and mental health) were assessed relative to ageand gender-matched control values. All the scores were reported as a difference from the age- and gender-matched normal value, with higher negative numbers indicating worse scores.

Study Cohort and Statistical Analysis. The NSN database was queried for all patients with a primary diagnosis of either lumbar disc herniation or lumbar spinal stenosis. Most of the data were collected before surgery (some patients may have had prior surgery elsewhere), and not all patients went on to have surgery. The disc herniation group was limited to patients between the ages of 18 and 65 years, and the stenosis group was limited to patients between the ages of 30 and 80 years. All the data used for this analysis were collected at NSN centers between January 1, 1995 and June 31, 1998.

Demographics, symptoms, health status, and clinical status

\begin{tabular}{|l|}
\hline Please answer YES or NO for each of the following questions \\
\hline $\begin{array}{l}\text { 37. In the past year, have you had } 2 \text { weeks or more during which you felt sad, } \\
\text { blue, depressed or when you lost all interest in things that you usually cared about } \\
\text { or enjoyed? }\end{array}$ \\
\hline $\begin{array}{l}\text { 38. Have you had } 2 \text { years or more in your life when you felt depressed or sad } \\
\text { most days, even if you felt okay sometimes? }\end{array}$ \\
\hline 39. Have you felt depressed or sad much of the time in the past year? \\
\hline
\end{tabular}

Figure 1. Three-question depression screener. all were compared between positive and negative depression screener patients. Standard tests were used for univariate analysis, including $t$ tests and $\chi^{2}$ tests. Multivariate linear regression was used to model the independent association between the depression screener and the individual scales of the SF-36. All analyses were performed using Stata 6.0 (StataCorp, College Station, TX).

\section{Results}

A query of the NSN database containing 21,195 patients found 2878 patients with a diagnosis of lumbar disc herniation and 3801 patients with a diagnosis of lumbar spinal stenosis. Positive responses to the depression screener were found in $38.4 \%$ of the patients with disc herniation and $36.4 \%$ of the patients with stenosis. Tables 1 and 2 demonstrate the association between the positive responses to the depression screener and the variables listed in the database. Patients with positive depression screeners had symptom-related variable responses indicating a higher percentage of time with worst symptoms, higher scores for least symptoms (i.e., the best feeling is worse than the best feeling of others), and more frequent thought that pain was worsening for both spinal stenosis and disc herniations. Patients with positive responses to the depression screener were more likely to have had to stop work because of symptoms, to be receiving workers' compensation insurance, and to have hired an attorney. Positive depression screener patients also were more likely to be unmarried, obese, smokers, and not educated beyond Grade 12.

The patients with spinal stenosis or disc herniation who had positive depression screeners were found to have lower scores than the patients with negative screeners on all the SF-36 subscales (Figures 2 and 3). Health perception, emotional health, mental health, vitality, and social functioning were the most clearly associated.

Multivariate logistic regression analysis was performed for the patients with positive depression screeners who had the clinical and demographic variables listed in Tables 1 and 2. According to the models, both disc herniation and stenosis patients who had a high school education or less, were unmarried, had hired an attorney, had symptoms lasting longer than 7 weeks, or were taking medications for other problems were significantly more likely to have a positive depression screener $(P<0.05)$.

Disc herniation patients who were unemployed, were nonwhite, were experiencing worse symptoms when symptoms were at their least severity, or were obese were significantly more likely to have a positive depression screener $(P<0.05)$. Stenosis patients who were receiving compensation, were experiencing more severe symptoms when symptoms were at their worst, were taking spine medications, or had diabetes were also more likely to have a positive screener $(P<0.05)$. 
Table 1. Characteristics of Lumbar Disc Herniation Patients With Positive Depression Screen

\begin{tabular}{|c|c|c|c|}
\hline & $\begin{array}{l}\text { Negative Depression } \\
\text { Screen }(\mathrm{n}=1774)\end{array}$ & $\begin{array}{l}\text { Positive Depression } \\
\text { Screen }(n=1104)\end{array}$ & $P$ Value \\
\hline \multicolumn{4}{|l|}{ Demographic factors } \\
\hline Age [average (SD)] (yr) & $41.3(10.5)$ & $41.0(9.8)$ & 0.197 \\
\hline Gender ( $\%$ female) & 38.0 & 45.2 & 0.000 \\
\hline Race (\% nonwhite) & 16.1 & 22.3 & 0.000 \\
\hline Education (\% high school education or less) & 28.0 & 44.2 & 0.000 \\
\hline Marital status ( $\%$ married) & 66.4 & 35.7 & 0.000 \\
\hline Work status (\% not working) & 40.4 & 57.1 & 0.000 \\
\hline (\% not working due to spine problem) & 21.6 & 35.0 & 0.000 \\
\hline $\begin{array}{l}\text { Physical demand of usual activities (\% with extremely } \\
\text { demanding activities) }\end{array}$ & 13.2 & 24.3 & 0.000 \\
\hline Attorney (\% hired) & 9.8 & 26.6 & 0.000 \\
\hline Compensation (\% receiving) & 20.9 & 38.5 & 0.000 \\
\hline \multicolumn{4}{|l|}{ Clinical factors } \\
\hline Symptom duration ( $\%>7$ weeks) & 69.9 & 83.8 & 0.000 \\
\hline Pain radiation (\% having some radiation) & 87.8 & 88.3 & 0.707 \\
\hline Symptoms at their worst (\% very severe) & 65.9 & 75.4 & 0.000 \\
\hline Symptoms at their least (\% severe or very severe) & 39.2 & 45.3 & 0.000 \\
\hline Symptoms on average ( $\%$ severe or very severe) & 58.6 & 66.5 & 0.000 \\
\hline $\begin{array}{l}\text { How often are symptoms at their worst (\% more than half } \\
\text { of the time) }\end{array}$ & 63.5 & 74.8 & 0.000 \\
\hline Improvement (\% with symptoms getting worse) & 37.7 & 53.5 & 0.000 \\
\hline Surgical history ( $\%$ had prior surgery) & 10.6 & 15.9 & 0.000 \\
\hline Smoking (\% smokers) & 16.0 & 24.0 & 0.000 \\
\hline Spine medications ( $\%$ taking) & 76.0 & 81.5 & 0.000 \\
\hline Other medications (\% taking) & 38.9 & 49.3 & 0.000 \\
\hline Asthma (\% with) & 1.0 & 2.4 & 0.004 \\
\hline Diabetes (\% with) & 2.8 & 4.5 & 0.015 \\
\hline Obesity (\% with) & 6.8 & 12.5 & 0.000 \\
\hline
\end{tabular}

\section{Discussion}

The results of this study clearly show that positive scores for the three-question depression screener are associated with greater symptom intensity in patients with least, average, and worse symptom intensity. Every patient experienced pain regardless of the responses to the depression screeners, but a patient scoring positive on the screener hald fewer pain-free periods. The patients with

Table 2. Characteristics of Lumbar Spinal Stenosis Patients With Positive Depression Screen

\begin{tabular}{|c|c|c|c|}
\hline & $\begin{array}{l}\text { Negative Depression } \\
\text { Screen }(\mathrm{n}=2419)\end{array}$ & $\begin{array}{l}\text { Positive Depression } \\
\text { Screen }(\mathrm{n}=1382)\end{array}$ & $P$ Value \\
\hline \multicolumn{4}{|l|}{ Demographic factors } \\
\hline Age [average (SD)] (yr) & $59.6(13.0)$ & $55.5(13.0)$ & 0.000 \\
\hline Gender (\% female) & 51.4 & 55.7 & 0.010 \\
\hline Race (\% nonwhite) & (0) 15.0 & 20.3 & 0.000 \\
\hline Education (\% high school education or less) & 35.9 & 48.9 & 0.000 \\
\hline Marital status (\% married) & 70.9 & 59.0 & 0.000 \\
\hline Work status ( $\%$ not working) & 39.4 & 33.1 & 0.000 \\
\hline (\% not working due to spine problem) & 9.3 & 21.1 & 0.000 \\
\hline Physical demand of usual activities ( $\%$ with extremely demanding activities) & 10.7 & 21.8 & 0.000 \\
\hline Attorney ( $\%$ hired) & 7.0 & 18.7 & 0.000 \\
\hline Compensation (\% receiving) & 11.6 & 28.2 & 0.000 \\
\hline \multicolumn{4}{|l|}{ Clinical factors } \\
\hline Symptom duration ( $\%>7$ weeks) & 88.6 & 93.6 & 0.000 \\
\hline Pain radiation ( $\%$ having some radiation) & 67.3 & 68.6 & 0.411 \\
\hline Symptoms at their worst (\% very severe) & 51.2 & 63.6 & 0.000 \\
\hline Symptoms at their least ( $\%$ severe or very severe) & 27.8 & 33.6 & 0.000 \\
\hline Symptoms on average ( $\%$ severe or very severe) & 51.5 & 62.4 & 0.000 \\
\hline $\begin{array}{l}\text { How often are symptoms at their worst (\% more than half } \\
\text { of the time) }\end{array}$ & 61.1 & 73.8 & 0.000 \\
\hline Improvement (\% with symptoms getting worse) & 53.2 & 64.3 & 0.000 \\
\hline Surgical history ( $\%$ had prior surgery) & 14.1 & 20.1 & 0.000 \\
\hline Smoking (\% smokers) & 11.1 & 19.5 & 0.000 \\
\hline Spine medications (\% taking) & 70.6 & 79.8 & 0.000 \\
\hline Other medications ( $\%$ taking) & 70.7 & 76.2 & 0.000 \\
\hline Obesity (\% with) & 9.5 & 13.6 & 0.000 \\
\hline Diabetes (\% with) & 7.8 & 9.7 & 0.050 \\
\hline
\end{tabular}


Figure 2. Herniated disc patient Short-Form 36-Item Health Survey scores.

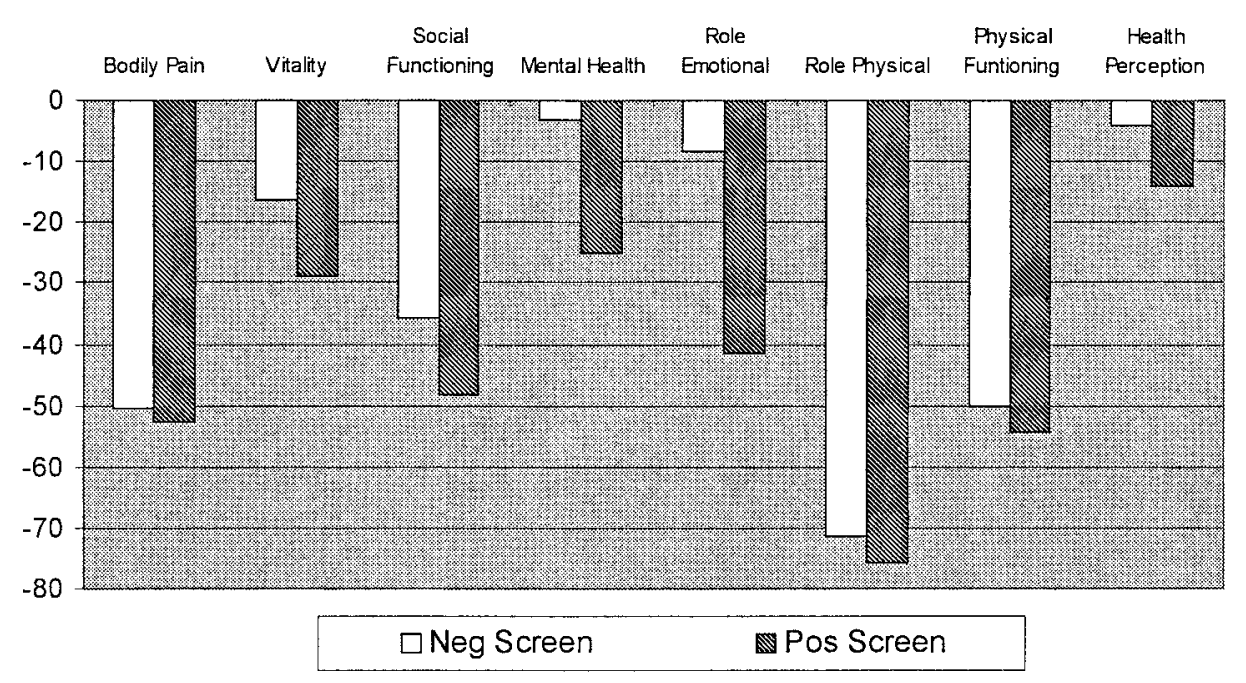

positive depression screeners had a constant pattern of pain with fewer pain-free periods as well as higher worst, average, and least symptom intensity. It is not clear whether the pain caused the depression or the depression preceded the pain. This is the antithesis of the belief of most physicians treating spine disorders that pain will wax and wane in most patients. ${ }^{16}$

This study found that patients with the most frequent reason for back surgery, lumbar disc herniations or lumbar spinal stenosis, have a relatively high prevalence of positive depression screener results. This finding is of interest because depression is associated with poor surgical outcomes. ${ }^{8}$ The current authors expect that only symptomatic patients are referred for surgery. In the study of Herron et $\mathrm{al}^{8}$ to determine the outcome of lumbar laminectomy for disc herniation and spinal stenosis, the Minnesota Multiphasic Personality Inventory predicted the outcome for lumbar disc herniations, but not for stenosis. Higher scores on this instrument for the hypochondriasis, depression, hysteria, psychopathic deviation, psychasthenia, and schizophrenia scales were found to be more accurate predictors of negative outcomes. ${ }^{8}$ It be of interest to determine how the depression screener predicts outcome from lumbar spine surgery.

Evidence from the current study shows that the depression scales were affected by the duration of symptoms. However, the study could not detect whether the depression preceded or resulted from the pain. (The database did not address the question whether the onset of depression was before or after a symptomatic lumbar disc herniation or stenosis pain) Other studies have shown that psychological and depression issues may precede or follow a presentation for back pain..$^{5-7,12}$ It is not uncommon for psychological symptoms to increase with chronic pain syndromes. A persistent pattern of pain can eventually cause wear and tear on the mind, increasing the propensity for psychological factors such as depression. 1

This study demonstrated that depression scores and pain severity are associated with litigation, workers' compensation, and use of a hired attorney. The scores for depression and symptom severity were adversely affected, as were the changes in SF-36 variables. This correlates with the study of Patrick et al, ${ }^{11}$ which demonstrated worse SF-36 scales in patients with workers'

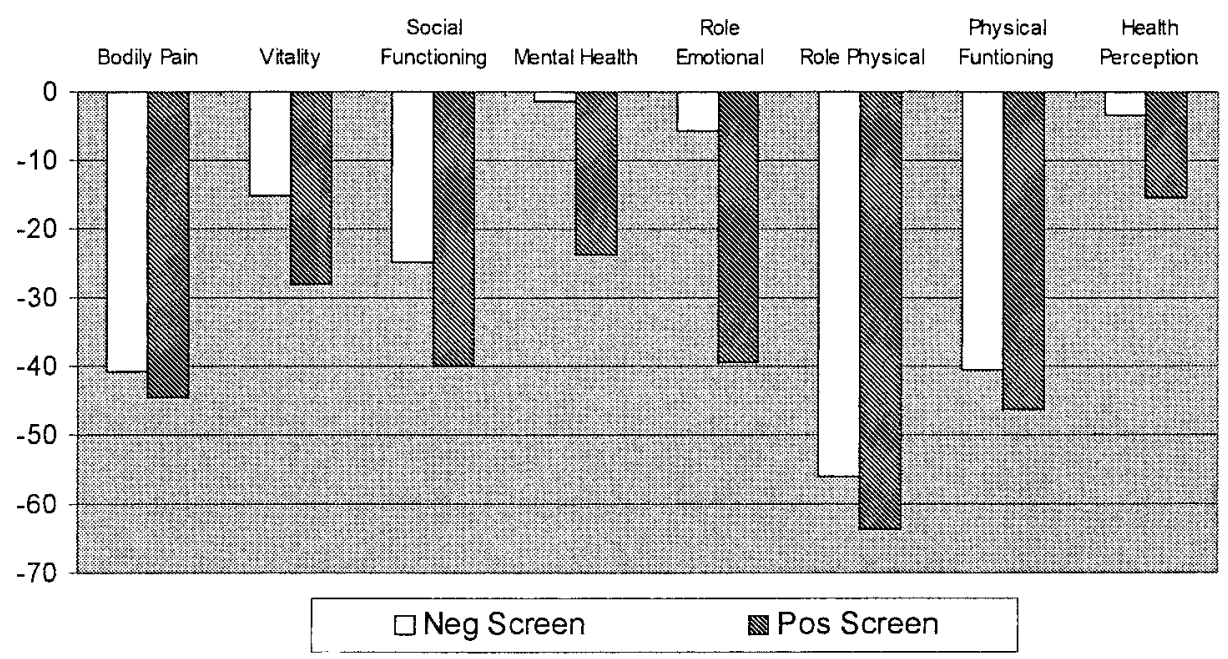

Figure 3. Spinal stenosis patient Short-Form 36-Item Health Survey scores. 
compensation insurance. However, Mendelson's 9 study demonstrated that litigation did not have an effect on chronic low back pain. In one surgical series for fusion-generated low back pain, workers' compensation insurance was associated with worse outcomes for patients after surgery. ${ }^{10}$ It was not determined whether depression had any association with the outcomes of surgery.

This study provided an interesting opportunity to compare the simple three-question depression screener with a larger, well-validated outcome instrument, the SF-36. The findings showed a close correlation between positive depression screener scores and psychological scales such as mental health, social functioning and emotional health. In addition, the association of positive depression screener scores with lower bodily pain, physical function, and role of physical condition scales was worth noting. Clearly, one drawback to the Depression Screener is its inability to measure changes in psychological well-being after favorable interventions. The Depression Screener assesses broad historical periods in which depression may have occurred and does not lend itself to measuring change over the time associated with treatment for lumbar stenosis or disc herniations.

The study of Berwick et $\mathrm{al}^{4}$ demonstrated that screening tests have value in detecting mental illness. Their study was even able to show how one question may be useful in detecting mental health issues. The questions in the current study used historical issues rather than current mental health issues. Which method is better for the studied population has not been determined.

\section{- Conclusion}

Depression, as indicated by a positive depression risk screener result, had a strong correlation with reported symptom intensity levels and general health status as measured by the SF-36 in patients with lumbar disc herniations or lumbar spinal stenosis. Workers' compensation absences from work also were correlated. On the basis of these findings, the authors conclude that even a simple three-question depression risk screener such as that included in the HSQ 2.0 provides important data more easily than use of the SF-36 alone to measure of health status.

Depression may significantly affect health status in patients with lumbar disc herniation or spinal stenosis. Alternatively, depression may result frequently from these conditions. Prospective studies are required to make this determination.
- Key Points

- The prevalence of positive responses to the threequestion depression screener was $36.4 \%$ among patients with spinal stenosis and $38.4 \%$ among patients with lumbar disc herniation.

- A positive response to the three-question depression screener was associated with poorer functional status and health-related quality of life as measured by the SF-36.

- A positive response to the three-question depression screener was associated with higher symptom intensity.

\section{References}

1. Albert TJ, Mesa JJ, Eng K, et al. Health outcome assessment before and after lumbar laminectomy for radiculopathy [discussion]. Spine 1996;21:960-53.

2. Albert TJ, Purtill J, Mesa JJ, et al. Health outcome assessment before and after adult deformity surgery: A prospective study. Spine 1995;20:2002-4.

3. Beck AT, Ward J-C, Mendelson M, et al. An inventory for measuring depression. Arch Gen Psychiatry 1961;4:561.

4. Berwick DM, Murphy JM, Goldman PA, et al. Performance of a five-item mental health screening test. Med Care 1991;29:169-76.

5. Boos N, Rieder R, Spratt KF, et al. Volvo Award in clinical sciences: The diagnostic accuracy of magnetic resonance imaging, work perception, and psychosocial factors in identifying symptomatic disc herniations. Spine 1995;1995:20.:2613-25.

6. Croft P, Papageorgiou A, Ferry S, et al. Psychologic distress and low back pain: Evidence from a prospective study in the general population. Spine 1995;20:2731-7.

7. Hansen F, Biering-Sorensen F, Schroll M. Minnesota Multiphaseic Personality Inventory profiles in person with or without low back pain: A 20-year follow-up study. Spine 1995;20:2716-20.

8. Herron L, Turner J, Clancy S, et al. The differential utility of the Minnesota Multiphaseic Personality Inventory: A predictor of outcome in lumbar laminectomy for disc herniation versus spinal stenosis. Spine 1986;11:847-50.

9. Mendelson G. Compensation, pain complaints, and psychological disturbance. Pain 1984;20:169-77.

10. Parker LM, Murrell SE, Boden SD, et al. The outcome of posterolateral fusion in highly selected patients with discogenic low back pain. Spine 1996; 21:1909-16.

11. Patrick DL, Deyo RA, Atlas SJ, et al. Assessing health-related quality of life in patients with sciatica. Spine 1995;20:1899-909.

12. Polatin P, Kinney R, Gatchel R, et al. Psychiatric illness and chronic low back pain: The mind and the spine: Which goes first? Spine 1993;18:66-71.

13. Radloff LS. The CES-D scale: A self-report depression scale for research on the general population. Appl Psychol Measure 1977;1:385.

14. Rost K, Burnam MA, Smith GR. Development of screeners for depressive disorders and substance disorder history. Med Care 1993;31:189-220.

15. Taylor VM, Deyo RA, Cherkin DC, et al. Low back pain hospitalization: Recent United States trends and regional variations. Spine 1994;19:1207-13.

16. von Korff M, Saunders K. The course of back pain in primary care. Spine 1996;21:2833-9.

17. Wells KB, Stewart A, Hays RD, et al. The functioning and well-being of depressed patients: Results from the Medical Outcomes Study. JAMA 1989; 262:914-19.

Address reprint requests to

Howard I. Levy, MD

2165 North Decatur Road

Decatur, GA 30033 


\section{Point of View}

\section{Francis J. Keefe, Daphne McKee, and Thomas Lynch}

Depression $^{1}$ can a major problem in patients who experience persistent pain. All too often, however, depression is underrecognized and undertreated. Depression not only is associated with adherence to medical treatments and health outcomes, but also can influence risk behaviors such as smoking, alcohol abuse, and overuse of prescription medications. Currently, self-report instruments (e.g., the Beck Depression Inventory) and clinical rating scales based on interviews (e.g., the Hamilton Rating Scale for Depression) probably are the most common methods for assessing depression in clinical practice. The article by Levy et al is important because it explores the utility of a brief, practical method for screening for depression that can be integrated easily into the clinical practice of spine surgeons. The three-question screener reduces patient and clinician burden because it involves fewer questions and does not require an interview of the patient.

One of the most interesting findings of this study is the relatively large number of patients with lumbar disc herniation $(38.4 \%)$ or spinal stenosis $(36.4 \%)$ who had positive screening results for depression. Depression typically is considered a problem in patients with long-standing, nonspecific musculoskeletal pain conditions, but is not addressed as often in patients with more specific spine pain disorders. Clinicians wishing to use the three-question depression screener, however, must be aware of two potential limitations.

First, a positive depression screener response does not necessary reflect a current depressive episode, but rather the presence of some depressive experience within the past year. Patients who score positive on this screener

From the Duke University Medical Center, Durham, North Carolina. Supported by grants from the National Institute of Mental Health (MH63429-01; NIMH grant MH01614), the National Cancer Institute (CA85219), the National Institute for Arthritis and Musculoskeletal and Skin Diseases (AR 46305), and the Arthritis Foundation, and in part by funding from the Fetzer Institute.

Device status/drug statement: The manuscript submitted does not contain information about medical devices or drugs.

Conflict of interest: Federal and Foundation funds were received in support of this work. No benefits have been or will be received from a commercial party related directly or indirectly to the subject of this manuscript. should receive a more careful and thorough assessment of depression (clinical interview or standardized selfreport measure such as the Beck Depression Inventory) before any treatment decisions are made.

Second, the items used in the screener depend on the patient's ability to identify and accurately report severe depressive symptoms (e.g., depressed mood, loss of interest). Medical patients have been shown to exhibit milder depressive symptoms when experiencing an episode of major depression. ${ }^{1}$ Patients who have difficulty labeling mood states (e.g., blue) or who do not experience anhedonia (loss of interest) may fail to endorse an item. Therefore, the screening tool as it is designed may fail to identify patients with major depression who have milder symptoms.

Finally, as noted by Levy et al, the association of the depression screener with higher levels of pain and lower quality of life is a correlational finding, meaning that it is impossible to determine whether depressive symptoms are the cause or the result of increased pain and decreased quality of life.

On the basis of the reported results, it appears that future research is warranted in exploring the utility and validity of the three-item depression screener used by Levy et al. It is hoped that future studies will incorporate some of the positive methodologic features of the current study (e.g., large sample size, collection of data from a national network of collaborating physicians). Future research should address the following key topics: how a positive depression screening result relates to formal diagnostic evaluations of depression, the degree to which the depression screening measure is sensitive to treatment interventions designed to reduce pain or depression, and the utility of the depression screening measure in predicting treatment outcome. In conclusion, it is hoped that the development of this depression screening measure will stimulate an upsurge in clinical research on depression in patients with spine pain.

\section{References}

1. Katon W. Will improving detection of depression in primary care lead to improved depressive outcomes? Gen Hosp Psychiatry 1995;17:1-2. 